\title{
ENSAIO
}

\section{A TEORIA DA EVOLUÇÃO COMO HARMONIA TEÓRICA - O PERCURSO HARMÔNICO DE CHARLES DARWIN}

\author{
TEORÍA DE LA EVOLUCIÓN COMO ARMONÍA TEÓRICA - EL CAMINO \\ ARMÓNICO DE CHARLES DARWIN
}

\author{
THEORY OF EVOLUTION AS THEORETICAL HARMONY - CHARLES \\ DARWIN'S HARMONIC PATH
}

DOI: $10.22481 /$ rbba.v10i01.8078

José D'Assunção Barros Universidade Federal Rural do Rio de Janeiro, Rio de Janeiro, Brasil https://orcid.org/0000-0003-3789-3378

ID Lattes: 7367148951589975

Endereço eletrônico: jose.d.assun@globomail.com

\section{RESUMO}

Como uma teoria se impõe nos meios científicos? Este ensaio busca responder a esta pergunta com o exemplo da Teoria da Seleção Natural de Darwin, utilizando o procedimento de compará-la a uma nova harmonia musical que precisou encontrar ouvidos preparados para a sua apreensão. Neste sentido, são discutidas algumas das estratégias de Darwin e seus colaboradores para granjear uma maior aceitação para a Teoria da Evolução no século XIX, e também as acomodações que precisaram ser feitas no texto darwiniano para enfrentar o meio científico e a sociedade de sua época.

Palavras-chave: Darwin; Teoria da Seleção Natural; Evolução; Biologia. 


\title{
RESUMEN
}

¿Cómo se impone una teoría en los círculos científicos? Este ensayo busca dar respuesta a esta pregunta con el ejemplo de la Teoría de la Selección Natural de Darwin, utilizando el procedimiento de compararla con una nueva armonía musical que tuvo que encontrar oídos preparados para su aprehensión. En este sentido, se discuten algunas de las estrategias de Darwin y sus colaboradores para lograr una mayor aceptación de la Teoría de la Evolución en el siglo XIX, así como las acomodaciones que se debieron hacer en el texto darwiniano para enfrentar el entorno científico y la sociedad de su tiempo.

Palabras clave: Darwin; Teoría de la selección natural; Evolución; Biología.

\begin{abstract}
How does a theory impose itself in scientific circles? This essay seeks to answer this question with the example of Darwin's Theory of Natural Selection, using the procedure of comparing it to a new musical harmony that had to find ears prepared for its apprehension. In this sense, some of the strategies of Darwin and his collaborators to gain greater acceptance for the Theory of Evolution in the 19th century are discussed, as well as the accommodations that had to be made in the Darwinian text to face the scientific environment and the society of his time.
\end{abstract}

Keywords: Darwin; Theory of Natural Selection; Evolution; Biology.

\section{A TEORIA DA SELEÇÃO NATURAL DIANTE DE SEU TEMPO IMEDIATO}

Nos dias de hoje, é extremamente familiar a Teoria da Seleção Natural de Charles Darwin, assim como a perspectiva evolucionista na Biologia. Tal abordagem é ensinada desde cedo nos bancos escolares, e não poderia ser de outra forma, pois as ciências só foram confirmando cada vez mais esta perspectiva teórica que começou a se consolidar no século XIX e que alçou o nome de Darwin a um dos cientistas mais influentes de todos os tempos. No entanto, para que a teoria da seleção natural fosse bem aceita, uma série de estratégias e 


\section{A TEORIA DA EVOLUÇÃO COMO HARMONIA TEÓRICA - O PERCURSO HARMÔNICO DE CHARLES DARWIN}

acomodações tiveram seu lugar nos meios científicos ingleses favoráveis à proposta de Darwin, e este também precisou fazer ajustes em seu texto para que sua teoria fosse bem aceita na sociedade mais ampla e nos meios cultos. Neste ensaio, discorreremos sobre estes aspectos de uma maneira original. Compararemos as teorias, ou as suas divulgações, a harmonias musicais que precisam vencer a resistência de diferentes grupos de ouvintes, para que estes passem a apreender mais confortavelmente os acordes que compõem tal teoria.

Começaremos por lembrar que a perspectiva taxonômica - introduzida mais sistematicamente no século XVIII, mas já presente em tateamentos classificatórios que remontam à Antiguidade Grega - pôde se beneficiar muito da perspectiva evolucionista introduzida na segunda metade do século XIX. De uma cuidadosa e sistemática descrição da variedade de seres vivos, passou-se, com a nova perspectiva teórica, a uma análise problematizada de suas conexões - tanto as sincrônicas (aquelas que se dão no interior de seus ecossistemas atuais) como as diacrônicas, que se estabelecem genealogicamente no âmbito de uma história que pode ser recuperada até os mais remotos instantes, nos chamados tempos préhistóricos. Em tese, e nos dias de hoje, nossa imaginação, datação e análise taxonômica podem recuar até a primeira protobactéria da qual descendem todos os seres vivos.

Com a consolidação da perspectiva evolucionista no século XIX, um novo critério de organização passava a interagir com as taxonomias que meramente inventariavam as características intrínsecas e as relações de semelhança entre os seres vivos: a busca de relações de parentesco evolutivo entre as várias espécies. Para tal projeto, a História irmanava-se com a Biologia através de uma teoria e prática que finalmente parecia merecer o título de História Natural, em uma extensão que poderia ser postulada como a mais rigorosamente apropriada para este termo. Em meados do século XX, a Cladística, aperfeiçoando nesta mesma direção as taxonomias que desde Lineu procuravam registrar a variedade dos seres vivos, empenhar-se-ia em construir a sua leitura das séries bióticas exclusivamente com base nas hipóteses de relações evolutivasi ${ }^{\mathrm{i}}$.

A incontornável assimilação de uma dimensão histórica e genealógica que deveria acompanhar o impulso de classificar os seres vivos, sempre e necessariamente, é um dos muitos sinais que revelam a importância e impacto da figura de Charles Darwin (1809-1882), e principalmente de sua obra, para a sua época e para a consolidação futura das ciências naturais. Sua importância e reconhecimento, aliás, só tendeu a se ampliar nos séculos seguintes. Embora a ideia de uma perspectiva evolucionista já estivesse no ar desde o princípio do século XIX, e 


\section{A TEORIA DA EVOLUÇÃO COMO HARMONIA TEÓRICA - O PERCURSO HARMÔNICO DE CHARLES DARWIN}

mesmo antes, A Origem das Espécies (1859), de Charles Darwin, tornou-se a obra matricial de uma nova concepção sobre a imensa variedade de formas vivas, e sobre como o mundo chegou a ela. Quero aproveitar essa menção para uma reflexão instigante sobre a possibilidade de pensarmos o conhecimento nos termos do desenvolvimento de harmonias teóricas, que lidam com construções complexas e conceituais que podemos assimilar a noções como a de 'acorde' e de 'harmonia musical'. As teorias podem ser pensadas como harmonias musicais que são propostas para os ouvintes que as assimilarão, ou que se sentirão desconfortáveis com elas; e os conceitos envolvidos nas diversas teorias científicas são como acordes musicais, sujeitos a serem apreendidos como consonâncias ou dissonâncias conforme seus ouvidos estejam ou não preparados para ouvi-los. Estas metáforas musicais acompanharão nossas reflexões sobre o percurso das realizações intelectuais decorrentes da perspectiva evolucionista que teve em Darwin o seu principal maestro.

\section{UMA COMPARAÇÃO ENTRE CIÊNCIAS E MÚSICA}

Na Música, sabe-se que os padrões de escuta se transformam com a história e com o tempo, ao atravessar os diversos espaços sociais e culturais nos quais de apresentam as variadas realizações musicais que vão sendo produzidas pelos compositores e performers, e que são concomitantemente assimiladas por diferentes tipos de ouvintes. Um par conceitual que permite o entendimento dos diferentes modos de apreensão da Música é o da oposição relativa entre dissonância e consonância. Estes conceitos possibilitam visualizar padrões de desconforto e conforto - ou de tensão e distensionamento - diante da apreensão de um som (ou, conforme veremos, também da apreensão de fenômenos os mais diversos). Este par conceitual, originário da arte musical, tem sido aplicado a áreas as mais distintas - como a Psicologia e as Ciências Sociais - e, conforme postularemos, também pode ajudar a compreender os movimentos de ideias que se dão na História das Ciências. Em vista disto, uma pequena digressão sobre o que são dissonâncias e consonâncias será bem oportuna.

Quando um cineasta utiliza música nas cenas de um filme, pode estar interessado em reforçar o clima de suspense, terror, angústia, desconforto, ou pode estar utilizando a linguagem musical como apoio para atingir o clímax da cena; de modo contrário, pode ser que o efeito que deseja obter seja o de produzir uma sensação de relaxamento e tranquilidade depois de alguns momentos de tensão. Uma cena de amor pode exigir uma melodia suave, e uma tomada erótica 


\section{A TEORIA DA EVOLUÇÃO COMO HARMONIA TEÓRICA - O PERCURSO HARMÔNICO DE CHARLES DARWIN}

pode se potencializar com fórmulas musicais impetuosas e ritmadas. A guerra pode requerer um fundo musical novamente tenso, e assim por diante. Pode ser, ainda, que o cineasta precise interromper uma sequência de acordes que se resolvem uns nos outros com o som mais intenso e impactante de todos: o silêncio.

A Música - arte parceira do Cinema, sem a qual não poderíamos ter uma linguagem fílmica tão bem elaborada como a que temos nos dias de hoje - presta-se bem a esta grande variedade de efeitos, porque a sua linguagem lida todo o tempo com tensões e distensões. 'Dissonância', na Música - o primeiro aspecto que vamos comentar - é a possibilidade de um som ser percebido como instável pelos ouvidos humanos. Este aspecto, que combina dados acústicos objetivos e inflexões subjetivas dependentes de fatores diversos, pode ser bem compreendido se o colocarmos em contraste com aquele que forma com ele um par natural: a 'consonância'. Se a dissonância remete à sensação de instabilidade, a consonância relaciona-se com a sensação de estabilidade. Estes efeitos surgem da relação entre dois ou mais sons, ou melhor, da possibilidade de perceber a relação entre dois sons de uma ou de outra maneira. A princípio, nenhum som é dissonante ou consonante por si mesmo, pois estas duas sensações básicas na estética musical só se produzem através da relatividade e confronto entre dois sons, além de sua inserção em um certo contexto de percepção. Podemos pensar aqui na noção musical que remete à relação entre duas notas - a de 'intervalo' - sendo que este pode se referir a duas maneiras distintas de os sons se relacionarem uns com os outros: "ao longo do tempo", ou "ao mesmo tempo". Esta relação será importante aqui, na verdade crucialii.

De fato, nas diversas músicas produzidas pelos compositores e instrumentistas, os sons podem se suceder uns aos outros (configurando o que chamamos de 'melodias'), ou podem ser emitidos simultaneamente, que é a situação que temos quando dois ou mais sons soam produzindo relações harmônicas. Tanto a simultaneidade como a sucessão de dois sons podem produzir essas sensações de tensão, instabilidade, desconforto - ou mesmo de repulsa auditiva - que chamamos de 'dissonâncias'. E é porque pode produzir dissonâncias, mais intensas ou mais moderadas, e contrabalançá-las concomitantemente com consonâncias, que a Música se apresenta não apenas como uma linguagem belíssima e fascinante, mas também como uma arte dotada de potencialidades as mais diversas: dramáticas, trágicas, empolgantes, meditativas. De resto, é preciso ressaltar que as dissonâncias e consonâncias estabelecem entre si uma dialética na qual uma depende da outra: um acorde dissonante pode se resolver, em seguida, em um acorde consonante; mas, depois disso, a composição musical pode progredir novamente para 


\section{A TEORIA DA EVOLUÇÃO COMO HARMONIA TEÓRICA - O PERCURSO HARMÔNICO DE CHARLES DARWIN}

uma sequência de tensões, e em seguida o discurso musical pode retornar a um ponto de conforto. A 'harmonia' - a arte de encadear acordes - baseia-se na técnica de articular acordes tensos ou instáveis com acordes estáveis ou relativamente estabilizados, resolvendo as tensões dos primeiros nos segundos, mas logo em seguida recaindo em novas tensões e distensões que dão movimento à música. Qualquer boa música, enfim, é constituída por um incessante jogo de instabilidades e estabilidades.

Desde já, é preciso ressaltar que o conceito de 'dissonância' é relativo: uma formação sonora que pode ter sido percebida em uma época ou cultura como dissonante pode passar a ser percebida por outra época ou meio cultural como consonante - como ocorreu, por exemplo, com os intervalos musicais de terças e sextas, que eram percebidos como dissonâncias pela sociedade europeia do período medieval e foram se tornando consonantes a partir da modernidade musical renascentista. Em várias oportunidades, a História da Música tem nos mostrado casos em que uma dissonância aparentemente "indomável" termina por encontrar seu bem ajustado lugar em outro sistema musical. O exemplo clássico é o do famoso diabolus in musica (tal como foi um dia chamado o intervalo 'si-fa' que tanto incomodava os ouvidos europeus medievais). No âmbito da estabilidade auditiva medieval, e no antigo sistema modal, este intervalo era considerado perturbador. Inserido no sistema tonal moderno, o trítono (intervalo 'si-fa') tornou-se uma dissonância fundamental e imprescindível para este sistema, pois era capaz de produzir tensões esteticamente úteis que seriam adequadamente resolvidas nos acordes seguintes ${ }^{\mathrm{iii}}$. Simplificando, se em um sistema o trítono foi evitado, aviltado ou mesmo perseguido, no outro sistema passou a ser aceito, e já não podíamos viver sem ele. A Música nos dá sempre interessantes exemplos, e vamos aproveitá-los como metáforas para compreendermos o papel do evolucionismo darwiniano ${ }^{\text {iv }}$ na nova harmonia teórica que começava a se afirmar cada vez mais no mundo europeu oitocentista da segunda revolução industrial.

Por ora, também é importante lembrar que o conceito de 'dissonância' foi assimilado por inúmeros outros campos, pois é particularmente eficaz para se referir a dois objetos ou aspectos que desenvolvem uma relação tensa um em relação ao outro. Antes de retomar nosso problema de História das Ciências - o da entrada da teoria evolutiva no cenário científico e social do século XIX - vamos dar apenas um pequeno exemplo de assimilação do conceito musical de dissonância em outro campo de estudos, que é o da Psicologia Social. Nesta área, o 


\section{A TEORIA DA EVOLUÇÃO COMO HARMONIA TEÓRICA - O PERCURSO HARMÔNICO DE CHARLES DARWIN}

conceito de "dissonância" foi reapropriado de muitas maneiras, mas foi Leo Festinger (19191989) o pioneiro na introdução do conceito de "dissonância cognitiva" (1957).

Ocorre "dissonância cognitiva" em diversos tipos de situações, como quando duas crenças não-compatíveis precisam ser compartilhadas pela mesma mente ${ }^{\mathrm{v}}$, quando um conhecimento ou padrão moral que um indivíduo pense possuir a respeito de algo se tensiona contra um modo de comportamento que o contradiz ${ }^{\mathrm{vi}}$, ou quando as expectativas que foram criadas por uma crença deparam-se contra uma realidade que a confronta ${ }^{\text {vii }}$. A dissonância cognitiva é aqui vista como o conflito que surge no indivíduo em seu processo de tomada de decisões, em decorrência da incoerência entre pelo menos dois elementos cognitivos. No livro 1984, de George Orwell, existe uma célebre passagem em que, sob tortura, o personagem central da trama - um indivíduo considerado subversivo pelo sistema repressor distópico - é obrigado a assimilar a ideia de que $2+2$ pode ter resultado 5 . A dissonância entre seu conhecimento matemático e a "verdade" que lhe é imposta o dilacera, mais do que a tortura, até que a sua própria mente parece se dissolver na resolução da dissonância. O “duplipensar", uma filosofia propugnada por aquele sistema distópico, seria precisamente a propriedade de transitar sem culpas e conflitos de um lado a outro de uma dissonância cognitiva não passível de solução, embora o autor não tenha colocado as coisas nestes termos, nesta obra de 1948.

O repertório de possibilidades disponíveis para o indivíduo que precisa resolver a dissonância cognitiva é variado. Como os compositores musicais, que fazem isto conscientemente e extraem potencialidades estéticas do uso das dissonâncias, os indivíduos comuns também aprendem a lidar com as suas dissonâncias, e desenvolvem estratégias para dissolvê-las, contorná-las, aprofundá-las, isolá-las umas das outras, ou o que mais seja necessário para conservar a sua harmonia interior. Algumas destas estratégias cognitivas ou comportamentais podem ser inconscientes, outras se apresentam como estratégias propriamente ditas, conscientemente aplicadas pelo ser pensante na sua vida diária ou nos momentos de crise.

Entre os dois elementos que produzem uma dissonância - como uma determinada crença e uma certa atitude que sejam inconsistentes entre si - pode-se conservá-los em compartimentos separados. Entre uma crença ou conhecimento arraigado que se confronta com uma realidade que os desmente, pode-se rejeitar a crença, ou então a própria realidade (“negação das evidências"). Há ainda a possibilidade de proceder à substituição de uma ou mais crenças envolvidas na dissonância (diminuir a dissonância), ou então o recurso de agregar novas informações ou crenças que permitirão elevar o nível de consonância do conjunto. Como na 


\section{A TEORIA DA EVOLUÇÃO COMO HARMONIA TEÓRICA - O PERCURSO HARMÔNICO DE CHARLES DARWIN}

Música, pode-se de fato produzir uma diluição da dissonância ao se incorporar um novo elemento, tal como ocorre na muito citada fábula A Raposa e as Uvas, de Esopo (620-564 a.C). Uma raposa faminta deseja as uvas que enxerga no alto de uma árvore. Quando percebe que não conseguirá alcançá-las, decide que não as deseja, pois provavelmente elas não estão maduras e saborosas. Ao agregar um novo elemento - ou uma nova nota ao acorde - ou seja, o palpite de que as uvas provavelmente estão amargas - a raposa dilui a tensão insuportável entre o desejo e o objeto inalcançável ${ }^{\text {viii }}$.

Para a questão que nos interessa, podemos perceber que esta teoria psicológica assimila elementos importantes da teoria musical: o conceito de dissonância e seu par, a consonância, e também a possibilidade de que os acordes dissonantes sejam "resolvidos" em acordes consonantes. Sustento que tal teoria não poderia ter sido pensada sem que os seus criadores, ao menos por um instante, adotassem um modo de imaginação musical. Talvez a crítica que possa ser feita aos autores seja a de que a dissonância é tratada essencialmente como um conflito que precisa ser resolvido. Essa possibilidade certamente está incluída na Música, mas não é a única. Polos de tensão, as dissonâncias também configuram liberdades - possibilidades de alçar voo para além de um horizonte estável que, uma vez atingido, já quer ser ultrapassado de novo. Além disso, as tensões são relativas: a nota ou o acorde que parece produzir tensão em um determinado contexto harmônico, em outro pode produzir um efeito diverso; e o acorde que parece estável em uma determinada situação musical, torna-se instável em outro contexto ${ }^{\text {ix }}$.

É importante ainda ampliarmos a percepção de que as dissonâncias podem ser trabalhadas esteticamente nas obras musicais - e de que, na verdade, a capacidade de lidar esteticamente com dissonâncias e consonâncias é uma das grandes habilidades dos compositores, da mesma forma que as dissonâncias também podem encontrar seu lugar na filosofia, na história, ou em quaisquer outros campos de saber. Em outras áreas de expressões artísticas como o Cinema e a Literatura, por exemplo, o jogo de tensões e distensões proporcionados pela musicalidade já tem sido amplamente empregado, e isto também pode ocorrer nos saberes científicos. Neste momento, retornaremos ao nosso tema central, mostrando que a teoria da evolução se afirmou como uma harmonia teórica bem demarcada por certas dissonâncias que precisaram se tornar mais familiares, e em alguns casos se resolver em situações menos tensas, para que a contribuição darwinista efetivamente pudesse conquistar o mundo científico e se espraiar como uma das mais impactantes e importantes formulações científicas de todos os tempos. 


\section{A TEORIA DA EVOLUÇÃO COMO HARMONIA TEÓRICA - O PERCURSO HARMÔNICO DE CHARLES DARWIN}

\section{O IMPACTO DE DARWIN EM SUA ÉPOCA E EM OUTRAS ÉPOCAS}

Não há como deixar de reconhecer que a Teoria da Seleção Natural, de Charles Darwin, impactou decisivamente o ambiente intelectual de sua época. Por um lado, suas proposições eram fortes e perturbadoras, e estavam prontas a afrontar muitas das crenças e convicções que seguiam bem vigentes na segunda metade do século XIX. As ideias evolucionistas são hoje muito familiares, pois são ensinadas, como aliás devem ser, já nos primeiros anos dos bancos escolares. Não é sobre elas que desejamos discorrer mais diretamente neste ensaio, mas pretendemos tangenciar de maneira criativa um pouco da sua história da sua aceitação ${ }^{\mathrm{x}}$. Também gostaríamos de comentar, ainda de passagem, que na mesma época de Charles Darwin um outro extraordinário cientista dava os primeiros passos em outro campo igualmente importante para a Biologia, que foi o dos estudos da Genética. Trata-se do biólogo e botânico austríaco Gregor Mendel (1822-1884), que já não teve a mesma sorte de ser reconhecido em sua época, apesar de trazer uma contribuição imprescindível que ficou esquecida por trinta e cinco anos até finalmente ser devidamente recuperada por cientistas a partir do século $\mathrm{XX}^{\mathrm{xi}}$. Mas, neste momento, nossa intenção é principalmente a de discutir o caso da consolidação do evolucionismo no século XIX, que logo despontaria como uma nova e decisiva maneira de compreender a grande variedade da vida no espaço-tempo terrestre.

Darwin não estava sozinho quando ocorreu o ponto de amadurecimento de suas ideias sobre uma lógica evolucionista regida pela "seleção natural” (um conceito por ele introduzido). Particularmente na Inglaterra, já se formava em determinados meios intelectuais um certo ambiente harmônico que poderia abrigar as novas perspectivas evolucionistas. O jovem naturalista Alfred Wallace (1823-1913), por exemplo, chegou a concepções bem similares às de Darwin na mesma época. Isso até mesmo acelerou o desejo de Darwin de publicar o quanto antes as observações sistemáticas que já vinha realizando há anos, como apoio à sua concepção evolucionista. Ele se demorava um pouco na decisão de tornar públicas as suas ideias porque sabia que elas perturbariam consideravelmente uma parte significativa da sociedade e do meio intelectual de sua época ${ }^{x i i}$. Talvez por isso, Darwin vinha adiando o inevitável momento em que introduziria as suas ideias no cenário científico de sua época, e o fato de ter percebido que também Wallace acabara de se aproximar dessas ideias por um caminho independente terminou 


\section{A TEORIA DA EVOLUÇÃO COMO HARMONIA TEÓRICA - O PERCURSO HARMÔNICO DE CHARLES DARWIN}

por precipitar a sua decisão de publicar simultaneamente um resumo de suas pesquisas sistemáticas e o novo sistema conceitual que propunha ${ }^{\text {xiii }}$.

$\mathrm{Na}$ verdade - embora radicalmente contrária ao que se pensava sobre a origem da vida nos meios comuns e na maior parte dos meios científicos - a concepção evolucionista já estava de alguma maneira no ar quando Darwin publicou seu emblemático livro sobre A Origem das Espécies (1859). Sem mencionar as já referidas pesquisas independentes de Alfred Wallace, dois outros pesquisadores - William Charles Wells (1813) e Patrick Mathew (1831) - já haviam desenvolvido nas décadas anteriores propostas que não estavam tão longe da perspectiva evolucionista apresentada por Darwin, tal como o próprio naturalista inglês reconhece no prefácio para a sexta edição de seu livro Origem das Espécies, publicada em 1876. Os receios de Darwin com relação à divulgação prematura das ideias evolucionistas não eram decerto infundados. A perspectiva evolucionista, obviamente, envolvia - e envolve ainda hoje - uma grande possibilidade de melindrar religiosos dogmáticos, uma vez que a sua explicação sobre o desenvolvimento da vida e sobre o surgimento das espécies não necessita da intervenção divina como variável independente. Ainda hoje, em certos ambientes - e bem mais do que isso deveria ocorrer - a teoria da evolução ainda provoca resistências, e já existem mesmo novas reações criacionistas às ideias de Darwin e às perspectivas evolucionistas que foram posteriormente aprimoradas, e isso em pleno século XXI.

\section{AS AÇÕES DE DARWIN E SEUS COLABORADORES PARA FORJAR OS NOVOS OUVIDOS CIENTÍFICOS}

Vamos nos concentrar na própria época de Darwin. Após a publicação de seu trabalho, aconteceu o que Darwin já temia (e que talvez o fizera se demorar na publicação de sua obra). Ao lado de uma parte do meio científico que se maravilhou com a nova lógica evolucionista esclarecida pelo naturalista inglês, Darwin também não deixou de receber críticas ferrenhas da Igreja, da Imprensa, e mesmo de setores mais conservadores dos meios científicos ${ }^{\text {xiv }}$. Tanto que, na segunda e na sexta edição de sua obra, Darwin fez algumas alterações, acrescentamentos e concessões que visavam abrandar a dissonância que sua obra produzira no quadro mais geral das concepções vigentes sobre a origem e variedade da vida. Estas alterações não prejudicaram a teoria como um todo, mas tentaram amenizar o seu impacto em grupos mais específicos de leitores. Para retomar a nossa metáfora musical, era como se, ao perceber que seus novos 


\section{A TEORIA DA EVOLUÇÃO COMO HARMONIA TEÓRICA - O PERCURSO HARMÔNICO DE CHARLES DARWIN}

acordes eram ainda muito dissonantes para alguns de seus ouvintes, Darwin procurasse suavizálos com timbres mais apropriados - ou como se estivesse tentando preparar melhor os ouvidos daqueles que poderiam escutar a nova música que estava propondo.

Na segunda edição de Origem das Espécies, Darwin acrescentou uma epígrafe extraída de um texto de autoria do bispo anglicano Joseph Butler (1692-1752) que discorre brevemente sobre a importância dos "milagres" e de um "fator inteligente" para a evolução. Ora. Tal epígrafe, particularmente no primeiro dos seus termos, está em franca dissonância com a lógica apresentada por Darwin, pois a argumentação do naturalista inglês em toda a sua exposição teórica conduz o leitor a perceber que Deus não precisaria, em absoluto, estar presente na equação da evolução dos seres vivos. Na verdade, a existência ou não de Deus não contradiz as ideias de Darwin e nem as apoia: são irrelevantes para o problema. Mas a ideia de que os milagres são importantes para a evolução das espécies realmente não soa bem dentro deste acorde: seria melhor dizer que Deus criou um sistema lógico, no qual o espaço-tempo e a seleção natural entravam como os principais artífices, do que evocar interferências divinas no processo evolutivo. Para conciliar o "sopro divino" com a perspectiva evolucionista - ou para ajustar as duas notas em um único intervalo - o gesto criador em relação à vida só deveria ter ocorrido uma única vez, pondo-se a partir daí o sistema biótico a se autorregular e a gerar as suas próprias transformações, o que implica colocar efetivamente de lado a imagem de que Deus tocara cada uma de suas criaturas de maneira independente ${ }^{\mathrm{xv}}$. De todo modo, a dissonância produzida pela introdução de um comentário religioso ficou mesmo relegada à epígrafe, sem afetar o conjunto da obra e a nova harmonia teórica que estava sendo proposta. Convenhamos, entretanto, que essa epígrafe dissonante prepara melhor os ouvidos conservadores, mesmo que depois se mostre francamente desalinhada de todo o resto da composição.

Posto isso, o sucesso da teoria da evolução foi estrondoso para uma parte significativa de públicos diversos - mostrando que outros ouvidos já ansiavam por uma nova harmonia teórica, capaz de esclarecer uma lógica subjacente à enorme variedade de formas de vida que vinham sendo esmiuçadas pelas pesquisas desenvolvidas por naturalistas desde princípios do século XVIII. Tanto que os 1250 exemplares da primeira edição de Origem das Espécies logo se esgotaram, e em apenas dois meses ocorreu a segunda edição. Dois anos depois (1861) ocorreria uma terceira edição, e sucessivamente surgiriam outras - em 1866, 1869 e 1872 - até chegarmos à sexta edição de 1876, que foi o último texto alterado da obra. Em todas as edições de sua obra maior, Darwin foi fazendo pequenos ou maiores ajustes: ou para amenizar as 


\section{A TEORIA DA EVOLUÇÃO COMO HARMONIA TEÓRICA - O PERCURSO HARMÔNICO DE CHARLES DARWIN}

dissonâncias ou para retomá-las, como se estivesse buscando o tom mais adequado para que a obra alcançasse um maior público, mas sem concessões desnecessárias que prejudicassem o caráter revolucionário da obra em seu âmago. Na sexta edição, por exemplo, o termo "Criador" aparece algumas vezes onde antes não estava, inclusive na página final, mas sempre de maneira que não afete em nada a argumentação desenvolvida ou suas implicações, quase sendo utilizado como um ornamento poético de linguagem.

Assim, da guerra da natureza, da fome e da morte, surge diretamente o mais excelso objeto que somos capazes de conceber: a produção dos animais superiores. Há grandeza nessa visão da vida, com seus vários poderes, insuflada que foi originalmente pelo Criador em algumas formas ou em uma, e no fato de que, enquanto este planeta prossegue seu giro em conformidade com a imutável lei da gravidade, de um começo tão simples evoluíram e continuam a evoluir infindáveis formas, as mais belas e fascinantes" ( $A$ Origem das Espécies).

De forma bem dosada e comedida, a palavra "Criador" parece atender à estratégia discursiva de suavizar os ouvidos dos muito religiosos, mas sem constranger a leitura científica com uma dissonância intragável ou incompatível que pudesse pôr toda a harmonia a se perder. Note-se que o sistematizador da teoria evolucionista deixa que se entreveja claramente o princípio de que possivelmente todas as formas de vida teriam sido provenientes de uma única ("a vida insuflada originalmente pelo Criador em algumas formas ou em uma") ${ }^{\mathrm{xvi}}$. As palavras são bem escolhidas, com a paciência de um compositor que seleciona meticulosamente os melhores timbres para a sua sinfonia, ciente de que logo ela terá de ser tocada pelas grandes orquestras e para os mais diversos auditórios. Por assim dizer, Darwin havia escrito o que tinha que escrever - ou composto a música necessária para uma nova época - mas precisava educar os ouvidos comuns para que pudessem receber sua obra sem maiores sobressaltos. O próprio encurtamento do título - que originalmente era Sobre a Origem das Espécies por meio da seleção natural, ou a preservação das raças favorecidas na luta pela vida - também revela o caminho da obra rumo a uma maior popularização. Com muito cuidado, Darwin parece bastante empenhado em preparar os ouvidos e mentes da época para o que tinha a dizer, e isso já ocorre desde a primeira edição de seu livro. Assim, o naturalista inglês preocupa-se em mostrar que suas conclusões não eram prematuras nem negligentes, e que haviam sido produtos de uma pesquisa de muitos anos, com observações recolhidas em viagens sistemáticas para pesquisar a fauna e flora em seus ambientes bióticos e geológicos. Literalmente se desculpa com o leitor pelo fato de citar na obra pormenores de caráter pessoal, que tinham o fito de mostrar que suas 


\section{A TEORIA DA EVOLUÇÃO COMO HARMONIA TEÓRICA - O PERCURSO HARMÔNICO DE CHARLES DARWIN}

conclusões não eram o "resultado de uma atitude precipitada". Esse cuidado também ajuda a explicar a demora de Darwin em publicar sua obra máxima.

\section{O PAPEL DE THOMAS HENRY HUXLEY NA PREPARAÇÃO DE UM NOVO AUDITÓRIO CIENTÍFICO PARA AS IDEIAS DE DARWIN}

Avancemos um pouco mais nesta instigante página da História Intelectual moderna. Outro personagem especialmente importante na preparação dos ouvidos da época para a nova harmonia teórica que Charles Darwin estava introduzindo, ao lado de outros cientistas que já vinham acenando de alguma maneira com a perspectiva evolucionista, foi o naturalista inglês Thomas Henry Huxley (1825-1895). Ele havia sido um dos poucos a quem Darwin confidenciara o resultado de suas pesquisas e de suas conclusões teóricas antes da publicação de Origem das Espécies (1859). Huxley dobrou-se à lógica da nova teoria assim que a conheceu, embora sem deixar de deixar de ter algumas reservas relacionadas a um aspecto ou outro, como a sua já mencionada crítica ao gradualismo que se expressava na sempre tão repetida ideia darwiniana de que "a natureza não dá saltos":

Como a seleção natural atua somente acumulando variações ligeiras, sucessivas e favoráveis, não pode produzir modificações consideráveis ou súbitas; só pode agir a passos lentos e curtos. Esta teoria torna fácil de compreender o axioma: Natura non facit saltum [a Natureza não dá saltos] (DARWIN, 1946, p. p. 535) ${ }^{\mathrm{xii}}$

À parte pontos como este, Thomas Huxley assimilou muito bem a perspectiva evolucionista de Darwin. Secretamente, trabalhou com bastante afinco para preparar os ouvidos científicos para a nova harmonia teórica, talvez ainda com maior eficácia do que o próprio Darwin. Graças à sua influência na cúpula científica inglesa, diversos cientistas idosos e arraigados à tradição terminaram por ser substituídos por cientistas mais jovens, com os ouvidos mais preparados para escutar as novas propostas teóricas trazidas por Darwin. Com esta estratégia, Huxley contribuiu bastante para que a comunidade científica inglesa derivasse para uma posição mais permeável a novidades científicas, o que se verificou efetivamente quando se anunciou o momento propício para a divulgação da teoria evolucionista ${ }^{x v i i i}$. Mas talvez o momento chave, destinado a pôr à prova a assimilação da nova harmonia teórica proposta pelo modelo evolucionista, tenha se dado em 30 de junho de 1860, em um debate em Oxford entre T. H. Huxley e o bispo anglicano Samuel Wilberforce (1805-1873). Sendo ambos extraordinários oradores, o debate mobilizou a assistência de centenas de espectadores. 


\section{A TEORIA DA EVOLUÇÃO COMO HARMONIA TEÓRICA - O PERCURSO HARMÔNICO DE CHARLES DARWIN}

\section{A ASSIMILAÇÃO SUBSEQUENTE DAS TEORIAS DE DARWIN}

A avaliação mais geral dos historiadores das Ciências sobre os resultados deste debate histórico, e sobre a sua repercussão junto à plateia imediata e ao público acadêmico da época, foi a de que o modelo darwinista terminou por se mostrar vitorioso, o que também se confirmaria no próprio trânsito destas últimas décadas do século XIX para o novo século. De fato, o novo modelo não tardaria a se consolidar como um novo paradigma biológico. Podemos dizer, para concluir a nossa metáfora, que a tônica evolucionista se tornou efetivamente a música dominante, tanto nos meios científicos como no ensino de Biologia em diversos níveis. Ao lado disso, o modelo evolucionista proposto por Darwin revelou-se tão impactante que não tardariam a surgir tentativas as mais diversas de aplicar esta harmonia teórica em outras áreas, gerando por vezes experiências que hoje estão desautorizadas como a de "evolucionismo social" - uma perspectiva que se queria empregar para sustentar a ideia de que algumas sociedades eram mais evoluídas do que outras (o que, no limite, dar-lhes-ia o direito de dominar ou tutelar as "sociedades inferiores"). Este modelo, que durante algum tempo conformou uma leitura da dinâmica social que passou a ser aceita entre outras, foi mais tarde desconstruído pela crítica acadêmica ao eurocentrismo e às pretensões colonialistas ${ }^{\mathrm{xix}}$.

$\mathrm{Na}$ Biologia, entrementes, a perspectiva evolucionista iria assumir o seu lugar de destaque, tornando-se consensual entre todos os praticantes deste campo, além de se abrir à possibilidade de se desdobrar em muitos desenvolvimentos posteriores, os quais renderiam não apenas a confirmação e aprimoramento da teoria biológica evolucionista, como também benefícios diversos para a humanidade. A harmonia conceitual hoje utilizada para compreender os processos evolutivos tanto aproveitou os conceitos introduzidos por Darwin - sobretudo o princípio de "seleção natural" - como introduziu novos aportes. Além da própria hipótese da seleção natural, hoje confirmada e elevada a um princípio que explica a evolução adaptativa das espécies, os conceitos de "deriva genética" e de "fluxo gênico" compõem uma tríade conceitual básica para a síntese moderna da Teoria da Evolução ${ }^{\mathrm{xx}}$. A dimensão fundamental que se acrescenta à perspectiva darwinista é a da própria Genética, com todos os seus extraordinários desenvolvimentos do início do século $\mathrm{XX}$ até os tempos recentes, sem deixar de considerar as descobertas de Mendel no século anterior (1865) sobre os modos de transmissão de características de duas fontes genéticas para o indivíduo vivo da geração 


\section{A TEORIA DA EVOLUÇÃO COMO HARMONIA TEÓRICA - O PERCURSO HARMÔNICO DE CHARLES DARWIN}

seguinte - uma contribuição científica à qual, aliás, só se deu a devida atenção no início do século XX.

Pode-se mesmo dizer que uma série de cientistas da primeira metade do século $\mathrm{XX}$ atuaram com especial eficácia na "harmonização" das teorias de Darwin e Mendel, articulando uma à outra, além de trazer à tona novas evidências que as comprovaram sucessivamente, e a cada vez de forma mais inquestionável. Estes aspectos nos levam a destacar enfaticamente que uma harmonia teórica, no âmbito das Ciências, não é produzida apenas por escolhas dos cientistas, mas também pelas possibilidades que se abrem com as descobertas efetivas e com as evidências que são incessantemente produzidas a partir de novas observações e experimentos. O horizonte científico de uma época abre certas possibilidades, e fecha outras, e as Ciências seguem em perpétuo aprimoramento testando a falibilidade de todas as teorias, abandonando os aspectos teóricos inadequados e selecionando os que se mostram aptos a seguir adiante. Quase parece se aplicar, à própria evolução de várias das ciências (seja de que modalidades de saber estejamos falando), os próprios pressupostos da seleção natural).

Para a questão que nos interessa mais diretamente neste momento, podemos considerar que tudo terminou por contribuir para esta consolidação do evolucionismo, na História das Ciências, como o modelo mais coerente para explicar a história natural - da crescente descoberta de fósseis que cada vez mais ajudaram a esclarecer as lacunas e ligações entre as diversas formas de vida, à decisiva e inquestionável contribuição das tecnologias que proporcionaram para a análise genética um conjunto de procedimentos tão precisos e eficazes como os que são disponíveis, nos dias de hoje, para a perícia criminal. Em diversas linhas científicas, em particular, o sucesso de um modelo teórico depende efetivamente das evidências que o apoiam e que o vão confirmando posteriormente, o que de fato se verificou de maneira decisiva no decorrer do século XX no que se refere à perspectiva evolucionista. A descoberta da estrutura do DNA, entre outras, reforçou mais do que nunca a perspectiva evolucionista. Além disso, o rastreamento genômico - que só se tornou possível a partir da bem articulada combinação dos extraordinários desenvolvimentos da Genética e da Informática nas últimas décadas - permitiu aos cientistas recuperar com considerável precisão a história da vida e da evolução, em uma impressionante viagem através do tempo que passou a operacionalizar os próprios corpos e organismos atuais como as suas principais fontes históricas, ao lado das já tradicionais fontes fósseis ${ }^{\mathrm{xxi}}$. 


\section{A TEORIA DA EVOLUÇÃO COMO HARMONIA TEÓRICA - O PERCURSO HARMÔNICO DE CHARLES DARWIN}

A recolha de material genômico de populações do planeta (de humanos e outros seres vivos), a tecnologia das máquinas de sequenciamento automático, e as montagens e análises dos dados obtidos através de algoritmos e redes de computadores - tudo isso conformando um complexo entremeado técnico que se tornou possível no alvorecer da sociedade digital permitiram, de fato, identificar uma possível origem única da vida, estudar as relações de parentescos entre as diversas espécies, historiar populações de diferentes seres vivos e iluminar os momentos em que ocorreram e se consolidaram mutações que terminaram por desdobrar novas formas de vida e produzir novos comportamentos adaptativos. Retornando no tempo à primeira bactéria, mãe de todas as formas vivas, os cientistas realizaram uma façanha só comparável ao retorno teórico no tempo que permitiu retroagir ao big-bang - ao próprio momento cósmico de nascimento do universo em que neste momento vivemos.

\section{CONSIDERAÇÕES FINAIS}

A proposta ensaística aqui realizada - a possibilidade de assimilar a linguagem musical, e, mais especificamente, a ideia de acorde a um modo de construir e trabalhar com conceitos nos diversos campos de saber - oferece um interessante campo de trabalho para temas os mais diversos. Comparar teorias científicas a harmonias musicais que precisam se impor a um auditório que precisa desenvolver novos padrões de escuta - de modo a não rechaçar o que lhe parece desconfortável ou dissonante - é um exercício interessante para se ver o desenvolvimento das teorias científicas de uma nova maneira, ou ainda a divulgação das teorias científicas em meios diversos.

O procedimento, na verdade, pode ser utilizado para quaisquer campos de saber, em quaisquer universos de estudo, pois em todas as disciplinas os pensamentos e práticas científicas se viram desafiados a enfrentar situações como a que Darwin e seus colaboradores precisaram superar. Deste modo, o que desenvolvemos neste ensaio - tomando como exemplificação o desenvolvimento da perspectiva darwiniana e darwinista diante do seu auditório científico imediato e, mais além, sua recepção em um outro tempo - foi a proposta de um procedimento teórico criativo, que se convida a que seja utilizado no âmbito de estudos da Biologia, Física, Ciência Política, História, Sociologia, ou, na verdade, de quaisquer outros campos de saber e com relação às mais diversas temáticas de estudo. 


\section{A TEORIA DA EVOLUÇÃO COMO HARMONIA TEÓRICA - O PERCURSO HARMÔNICO DE CHARLES DARWIN}

\section{REFERÊNCIAS}

ARENDT, Hannah; Eichmman em Jerusalém: Um relato sobre a banalidade do mal. São Paulo: Companhia das Letras, 1999.

BROWNE, J. Darwin in Caricature: A Study in the Popularisation and Disseminatin of Evolution. Proceedings of the American Philosophical Society, $n^{\circ} 145$ (4), p.496-509, 2001.

DAWKINS, R. A Grande História da Evolução. São Paulo: Companhia das Letras, 2009.

DARWIN, Ch. A Origem das Espécies. Porto: Lello \& Irmãos, 1946 [original: 1850].

ELSTER, J. Sour Grapes: Studies in the Subversion of Rationality. Cambridge: Cambridge University Press, 1983.

FESTINGER, L; RIECKEN, W. e SCHACHTER, S., When Prophecy Fails: A Social and Psychological Study of a Modern Group that Predicted the End of the World. Minnesota: University of Minnesota Press, 1956.

GOULD, S. J, (org.). As Cartas de Charles Darwin (1825-1859). São Paulo: UNESP, 1999. . The Panda's Thumb. New York: W. W. Norton, 1980. Ever Since Darwin. New York: W. W. Norton, 1977.

HENNIG. W. Phylogenetic Systematics. Illinois: University of Illinois Press, 1999 [original: 1950].

HUXLEY, Th. Darwiniana: a origem das espécies em debate. São Paulo: Madras, 2006.

HUXLEY, Th. "Evolution in Biology" In: Collected Essays II: Darwiniana. London: Macmillan, 1893-94. pp.187-226 [original: 1878].

PLANCK, Max. Scientific Autobiography and Other Papers. New York: Philosophical Library, 1949.

SCHOENBERG, A. Harmonia. São Paulo: Unesp, 1999 [original: 1911].

TENNEY, J. A history of 'consonance' and 'dissonance'. New York: Excelsior Music Publishing Co., 1988.

WEIKART, Richard. From Darwin to Hitler: evolutionary ethics, eugenics, and racism in Germany. New York: MacMillan, 2004.

WHITE, Paul. Thomas Huxley: Making the Man of Science. Cambridge: Cambridge University Press, 2003. 


\section{A TEORIA DA EVOLUÇÃO COMO HARMONIA TEÓRICA - O PERCURSO HARMÔNICO DE CHARLES DARWIN}

\section{NOTAS}

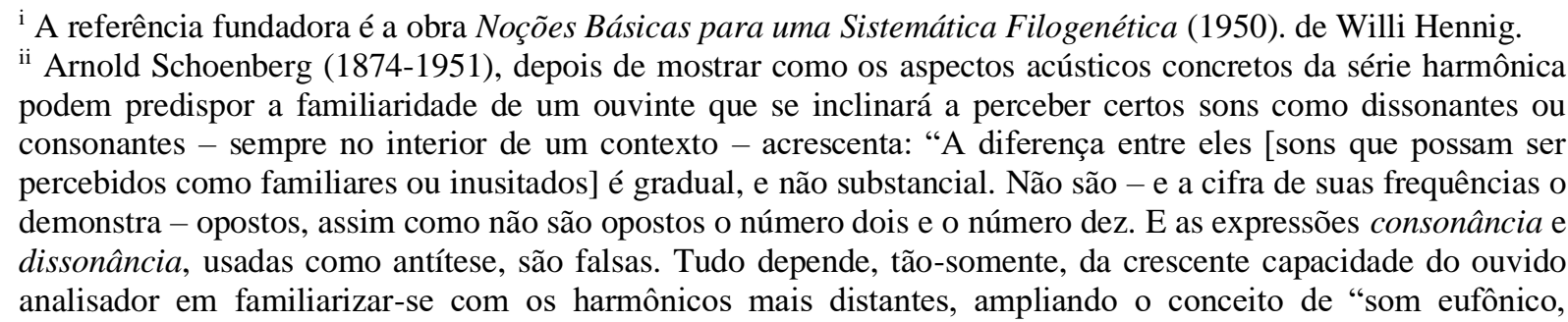
suscetível de fazer arte", possibilitando, assim, que todos esses fenômenos naturais tenham um lugar no conjunto" (SCHOENBERG, 1999, p.59).

iii A designação (diabolus in musica) aparece mais tardiamente, já no século XVII, no tratado de um músico eclesiástico conservador (Gradus ad Parnassum, de J. J. Fux, 1725). Mas os músicos católicos medievais possivelmente não rejeitariam essa designação que tão bem representa o incômodo que, para eles, era trazido pelas dissonâncias contidas no trítono - um intervalo não mais de 'quinta justa' (a chamada consonância perfeita), mas sim de 'quinta diminuta'.

iv Neste texto, o adjetivo "darwiniano" se aplicará àquilo que o próprio Darwin propõe sobre a sua teoria da evolução das espécies, e o adjetivo "darwinista" se aplicará aos desenvolvimentos e reapropriações que outros autores e colaboradores propuseram ou propõem a partir de uma leitura da mesma.

${ }^{v}$ Tal pode ocorrer, por exemplo, com um indivíduo que possua crenças religiosas em franca contradição com sua perspectiva científica.

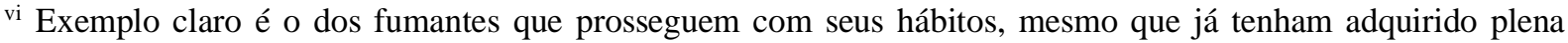
convicção de que os cigarros prejudicam imensamente a saúde. Também está em dissonância cognitiva deste tipo o "torturador bom chefe de família", que no seio de sua estrutura familiar é um pai amoroso e um vizinho solidário, mas que nos porões do aparelho repressivo em que trabalha pratica crimes contra a humanidade. A "banalidade do mal”, examinada por Hannah Arendt, também se aplica a este tipo de tensionamento. Sobre este último tema, cfe. ARENDT, 1999.

vii $\mathrm{O}$ caso do candidato à Presidência da República no qual o indivíduo depositou todas as suas esperanças, elevando-o à categoria de "mito", e que depois se revelou uma escolha absurda, pode ser citado como um exemplo eloquente. Incapazes de "resolver" a contradição entre sua crença anterior e a própria realidade que depois se apresenta, os indivíduos preferem fechar os olhos para a realidade de modo a manter a crença original intocada; ou, então, rompem com o mito que haviam construído previamente, em um contramovimento que pode ser tão violento como a decepção que os dilacera. Um dos primeiros casos investigados por Festinger e publicados como apoio à sua proposta teórica foi o da seita que acreditava que uma catástrofe com data marcada destruiria o planeta Terra. Quando a profecia não se realizou, diversos membros da seita preferiram não abandonar a crença original e inventar explicações para a não-concretização da catástrofe. Em termos simples, resolveram a contradição produzida pela dissonância cognitiva elaborando atalhos explicativos que preservassem o pensamento original (FESTINGER, RIECKEN e SCHACHTER, 1956).

viii Esta já clássica ilustração sobre a 'dissonância cognitiva' foi utilizada por Jon Elster, em seu livro Uvas Amargas: sobre a subversão da racionalidade (1983). O modo de resolução da dissonância decidido pela raposa - ou por indivíduos que utilizem procedimentos similares diante de situações diversas - foi chamado por Elster de "formação adaptativa de preferências" (ELSTER, 1983, p.123). No caso, trata-se de adaptar o desejo ao que a realidade objetiva parece oferecer.

ix Além disso, a História da Música mostra que o que é percebido como tensão pelos ouvidos humanos inseridos em um determinado contexto histórico-cultural, pode passar a ser percebido como consonância ou dissonância moderada em outro. A sensibilidade com relação ao efeito dissonante, enfim, transmuta-se com o tempo. Esta possibilidade também pode ser considerada e assimilada pelo uso do conceito de 'dissonância' em concepções teóricas desenvolvidas em outros campos de saber. / Sobre a história das mudanças de percepções com relação a dissonâncias musicais (cfe. TENNEY, 1988 e WEBERN, 2020).

x Apenas para situá-la nos seus pontos essenciais, podemos resumir os cinco princípios que interagem na teoria evolucionista proposta por Darwin. Além de reconhecer que todas as espécies são mutáveis (1), considera-se que todos os organismos descendem - através de um processo de evolução ramificada - de um ancestral comum (2). Para Darwin, a evolução é sempre gradual (3) - aspecto que foi matizado por biólogos que o sucederam. Como regra geral, as espécies tendem a se multiplicar (4). Por fim - e talvez possamos situar esta como a nota fundamental do acorde de "evolução" proposto por Darwin - os indivíduos e espécies estão sujeitos à lei da Seleção Natural. Não será o caso de analisar este acorde conceitual no momento, mas pode-se facilmente observar que 


\section{A TEORIA DA EVOLUÇÃO COMO HARMONIA TEÓRICA - O PERCURSO HARMÔNICO DE CHARLES DARWIN}

existe uma perfeita interação (ou relação intervalar) entre as diversas notas que compõem o conceito de "evolução" conforme a perspectiva darwinista: 'mutabilidade da vida', 'ramificação a partir de um ancestral comum', 'gradualismo', 'tendência à multiplicação de espécies' e 'seleção natural'.

xi Gregor Mendel (1822-1884) era naturalista, especialmente dedicado à Botânica, e meteorologista; mas também era um monge agostiniano. Formulou as leis que regem a transmissão dos caracteres hereditários, e as apresentou à comunidade científica em 1865. A extraordinária importância do seu trabalho não foi reconhecida senão após a virada para o século XX. Os ouvidos não pareciam estar prontos para a escuta da harmonia teórica que começou a desenvolver com base em uma sólida argumentação e em experiências muito concretas a partir da análise de cruzamentos de ervilhas. Com ele, a Genética dava os seus primeiros passos, embora isto só tenha sido reconhecido depois. O século seguinte formularia um novo paradigma biológico colocando a interagir a teoria evolucionista de Darwin e a genética mendeliana - ou "harmonizando" estas duas perspectivas teóricas, se quisermos tomar mais uma expressão emprestada à Música - sendo que depois os estudos genéticos tomaram rumos surpreendentes. As descobertas de Mendel, entretanto, só se beneficiaram de uma ampla publicação muitos anos depois de sua morte. xii Stephen Jay Gould (1941-2002) chamou esta longa espera de "a protelação de Darwin” (1977). Alguns aspectos se combinaram para motivá-la. Darwin havia lido em 1844 um livro intitulado Vestígios da História Natural da Criação, escrito por um jornalista anônimo. A obra propunha uma perspectiva evolucionista, mas sem basear-se em sólidas evidências de pesquisa e sem apoiar-se em uma linguagem científica, tendo despertado uma implacável crítica do público religioso. A recepção furiosa deste livro fez Darwin perceber que precisava assegurar duas coisas antes de impactar a sociedade inglesa com uma obra tão desafiadora como a sua Origem das Espécies. Precisava fundamentá-la em tantos dados quanto pudesse, e precisava se legitimar mais como cientista. Para assegurar este último aspecto, resolveu se desviar estrategicamente para a elaboração de um livro mais técnico e específico de história natural, sobre as cracas, de modo a conquistar um lugar mais visível entre os naturalistas ingleses antes de lançar sua grande obra. Também receava as críticas ferozes dos religiosos e dos setores intelectuais mais conservadores.

xiii Darwin, que vinha trabalhando na sua teoria da evolução há já cerca de vinte anos, teve de fato uma terrível surpresa ao receber em 1858 uma carta do jovem naturalista Alfred Wallace, que vinha desenvolvendo pesquisas nas Ilhas Moluscas, na Indonésia. Wallace queria a sua opinião, como naturalista mais experimentado, sobre a teoria evolucionista que havia desenvolvido, e suas ideias eram de fato muito próximas das de Darwin. Como mencionamos na nota anterior, Darwin aguardava estrategicamente um momento mais apropriado para a publicação de suas próprias ideias, pois temia que sua carreira pudesse ser prejudicada pela inevitável perturbação que sua teoria iria provocar. Mas quando viu que Wallace chegara a conclusões similares, de forma inteiramente independente, quase entrou em desespero. Teria escrito em uma carta a seu amigo Charles Lyell uma frase sintomática: "toda a minha originalidade será esmagada". Esta tensão se resolveu quando Charles Lyell e o botânico Joseph Dalton Hooker propuseram que os dois trabalhos fossem apresentados simultaneamente à Linnean Society of London. Isso ocorreu em $1^{\circ}$ de julho de 1858, e logo depois Darwin se apressou a dar uma forma final à sua famosa obra A Origem das Espécies (1859).

xiv Contra Darwin, não faltaram nos jornais ingleses da época as caricaturas depreciativas que mostravam o naturalista inglês como um macaco. Cfe, BROWNE, 2001, p.496-509.

${ }^{x v}$ Diz-nos Charles Darwin, em uma das partes iniciais de sua obra: "Quando analisamos o problema da origem das espécies, compreendemos facilmente que o naturalista que analisa as afinidades mútuas dos seres vivos, suas relações embriológicas, sua distribuição geográfica, a sucessão geológica e demais fatos semelhantes chegue à conclusão de que as espécies não devam ter sido criadas de maneira independente, mas que, da mesma forma que as variedades, descendam de outras espécies. Todavia, essa conclusão, mesmo sendo bem fundamentada, seria insatisfatória, a não ser que se pudesse mostrar como as incontáveis espécies que existem nesse mundo teriam sido modificadas, até alcançarem a perfeição estrutural e de coadaptação que de forma tão efetiva excita a nossa imaginação" (DARWIN, 1946, p.31).

xvi Darwin iria mais tarde oscilar diante desta concessão discursiva - o uso da palavra "Criador" no desfecho de uma teoria que trouxe como uma das grandes originalidades a possibilidade de prescindir desta referência. Na verdade, a teoria evolucionista até mesmo poderia explicar a poderosa ilusão de que a exuberante e sofisticada perfeição dos organismos vivos revelava necessariamente um projeto meticulosamente realizado por uma inteligência superior. Em uma carta ao botânico inglês Josep Dalton Hooker (1817-1911), Darwin comenta seu arrependimento de se ter deixado intimidar pela opinião pública nas edições posteriores de seu livro Origem das Espécies. Sobre o impulso inicial que institui a vida, Darwin diz nesta carta que ela teria aparecido através de algum processo totalmente desconhecido, mas que especular sobre isto, naquele momento - mesmo cientificamente - teria sido tão profícuo quanto especular sobre a origem da matéria. Sobre as cartas de Darwin, cfe. Gould (1999). 


\section{A TEORIA DA EVOLUÇÃO COMO HARMONIA TEÓRICA - O PERCURSO HARMÔNICO DE CHARLES DARWIN}

xvii A fixação de Darwin na ideia incondicional de que "a Natureza não dá saltos”, por outro lado, foi relativizada por outros evolucionistas já na própria época de Darwin, como Thomas Huxley (1825-1895), um cientista que se tornou tão fiel à teoria darwinista da evolução que chegou a ficar conhecido como "o buldogue de Darwin": "Realmente, sempre pensamos que o sr. Darwin criou um empecilho desnecessário ao aderir tão estritamente à sua citação favorita: Natura non facit saltum. Em nossa opinião, suspeitamos que, algumas vezes, ela [a Natureza] faça saltos consideráveis com respeito à variação, e que esses saltos dêem origem a alguns dos lapsos que parecem existir na série de formas conhecidas" (HUXLEY, 2006, p.48). Mais tarde, com os desenvolvimentos da teoria evolucionista no século XX, surgiu a perspectiva teórica do Equilíbrio Pontuado, proposta por autores como Stephen Jay Gould e Niles Elredge (1972). Este desdobramento teórico procura dar a perceber uma alternância entre longos períodos de estabilidade no que concerne ao surgimento de variações significativas (fase de equilíbrio) e períodos em que ocorrem rápidas alterações. Além disso, Gould argumenta que a mudança evolutiva é bem mais intensa e rápida nos nichos isolados, com populações pequenas, do que nas áreas centrais compartilhadas por populações grandes (GOULD, 1980, p.182-184).

xviii Max Planck (1858-1957), em sua Autobiografia Científica, registra os seguintes comentários sobre as dificuldades e resistências que precisam ser enfrentadas pelos paradigmas revolucionários que se confrontam contra uma tradição científica por demais arraigada aos antigos modos de ver as coisas: "uma nova verdade científica não triunfa convencendo seus oponentes e fazendo com que vejam a luz, mas sim porque seus oponentes finalmente morrem e uma nova geração cresce familiarizada com ela" (PLANCK, 1949, p.33-34). Huxley parecia conhecer bastante bem esta tendência inercial da maior parte dos cientistas mais antigos. Sobre Thomas Huxley, cfe. White (2003).

xix $\mathrm{O}$ primeiro empenho de derivação mais sistemática da perspectiva biológica do evolucionismo para a antropologia e sociologia pode ser atribuído ao filósofo, biólogo e antropólogo Herbert Spencer (1820-1903), também inglês, que procurou transpor essa harmonia teórica que foi o evolucionismo darwinista para o entendimento de todos os níveis da atividade humana, inclusive a sua organização social e progresso tecnológico. Para utilizar os termos que estamos encaminhando em nossa proposta de leitura, Spencer teria transposto alguns acordes conceituais da teoria das espécies para novos problemas já tingidos por uma tonalidade antropológica. Esta aplicação foi posteriormente muito distorcida. A ideia de "sobrevivência do mais apto" - uma expressão que foi, aliás, cunhada por Spencer - foi desvirtuada mais tarde para justificar opressões sociais, e até mesmo Hitler chegou a propor a ideia de que a "luta entre as nações" seria o equivalente político planetário da "luta das espécies", além de tentar encontrar no evolucionismo uma justificativa para as práticas eugenistas. Ao mesmo tempo, o eventual desvirtuamento hitlerista de acordes conceituais evolucionistas - que aconteceu ao lado de inúmeros outros desvirtuamentos no bizarro Frankenstein teórico elaborado por Hitler e por seus mentores e seguidores foi mais tarde evocado por correntes criacionistas para tentar denegrir o próprio evolucionismo biológico. Um opositor das ideias darwinistas, Richard Weickart (2004), tem se empenhado em tentar desvalorizar a teoria evolucionista com o argumento (não científico) das "conseqüências adversas" - que é o tipo de argumentação que procura desvalidar uma teoria alegando apenas que as conseqüências da sua adoção podem ser danosas. Tudo isso mostra que, uma vez criada uma certa 'harmonia teórica' - um sistema articulado e coerente de 'acordes conceituais' aplicado a um certo conjunto de problemas - nada impede que surjam outros usos, e mesmo distorções, para a elaboração teórica proposta. Empunhando-se conceitos, até mesmo podem ser travadas guerras teóricas e pragmáticas. / Outro exemplo de transposição da harmonia teórica evolucionista, agora para o âmbito da Geografia, foi proporcionado pelo determinismo geográfico de Friedrich Ratzel (1844-1904), um geógrafo alemão que argumentou que a luta pela existência era principalmente uma luta pelo espaço.

xx O "fluxo gênico" relaciona-se à transmissão de alelos de uma população a outra, em decorrência, por exemplo, de encontros migratórios. Em uma nota anterior, destacamos que, há 50.000 anos, teria ocorrido um fluxo gênico entre neanderthais e Homo sapiens, fora do ambiente africano, de modo que os homens atuais não-africanos apresentam entre 1,8 e 2,6\% de genes neanderthais. Os "fluxos gênicos" acrescentam uma nota de complexidade ao processo evolutivo, assim como as "derivas genéticas", que já se referem aos eventos aleatórios que podem mudar a frequência de um alelo em certa população.

xxi Os mapeamentos de genomas - em especial o do genoma humano - não tinham por objetivo central esclarecer a história do bioma e da humanidade, mas sim permitir avanços na medicina e também beneficiar outras áreas como a agricultura e nutrição. No entanto, a Genômica Comparada terminou por possibilitar outras conquistas como a compreensão da história das populações humanas ancestrais e do próprio desenvolvimento evolutivo das várias espécies vivas ou já extintas. Adicionalmente, as informações derivadas do Projeto Genoma Humano ajudaram a desconstruir quaisquer perspectivas errôneas de que a humanidade atual poderia ser vista como constituída por diferentes raças ou subespécies. Já no que concerne às hipóteses evolucionistas, uma das contribuições dos mapeamentos de genoma foi a de mostrar a semelhança de vários genes humanos com outras 
espécies de seres vivos - das bactérias aos vermes, ratos e macacos. O projeto confirmou que todos os seres vivos que habitam a Terra são primos distantes, ligados por relações de parentesco que podem ser mapeadas. 